\title{
Isomeric pyridyl-thiazole donor units for metal ion recognition in bi- and tri-metallic helicates $\dagger$
}

\author{
Sam Bullock, ${ }^{a}$ Lisa J. Gillie, ${ }^{a}$ Lindsay P. Harding ${ }^{a}$ Craig R. Rice, ${ }^{* a}$ \\ Thomas Riis-Johannessen $^{b}$ and Martina Whitehead ${ }^{a}$
}

Received (in Cambridge, UK) 5th May 2009, Accepted 12th June 2009

First published as an Advance Article on the web 2nd July 2009

DOI: $10.1039 / \mathbf{b 9 0 8 9 1 1 j}$

Linking two isomeric tridentate $\mathrm{N}$-chelates together produces a hetero-ditopic ligand capable of selectively binding $\mathbf{H g}^{2+}$ and $\mathrm{Zn}^{2+}$ ions in a double-stranded helicate.

Underlying recognition phenomena in multi-component self-assembly processes can be exploited for the site-specific inclusion of different metal ions into polymetallic arrays. In the field of metallosupramolecular chemistry this is typically accomplished by programming either (i) the denticity of or (ii) the nature of the donor atoms in the binding sites of a polytopic ligand, prior to self-assembly with target metal ions. ${ }^{1}$ Segmental oligo-N-heterocyclic ligands that contain both tridentate and bidentate chelates, or the ability to partition as such, exemplify the first of these approaches. ${ }^{1}$ They form double-stranded hetero-bimetallic helicates with metal mono- and dications due to the preference of the former (e.g. $\left.\mathrm{Ag}^{+}, \mathrm{Cu}^{+}\right)$for tetrahedral coordination geometry and that of the latter $\left(e . g . \mathrm{Cu}^{2+}, \mathrm{Co}^{2+}, \mathrm{Fe}^{2+}\right)$ for octahedral coordination geometry. ${ }^{1}$ When two such ligands are arranged appropriately, e.g. a co-aligned head-to-head ( $\mathrm{HH}$-) fashion in the case of a simple ditopic ligand, the resulting assembly features four- and six-coordinate sites into which the respective $\mathrm{M}^{+}$and $\mathrm{M}^{2+}$ ions are accommodated according to their respective geometry preferences. ${ }^{1,2}$ The second strategynamely, the use of a polytopic ligand whose binding sites vary with regards to the nature of their donor atoms - has been applied with considerable success by Piguet and Bunzli et al. for the challenging task of selectively incorporating different lanthanide ( $\mathrm{Ln})$ trications into triple-stranded helicate arrays. ${ }^{3}$ They demonstrated that the self-assembly of ditopic ligands comprised of a triimine $\mathrm{N}_{3}$ - and a diimine/amide $\mathrm{N}_{2} \mathrm{O}$-domain, with various $\mathrm{Ln}-\mathrm{Ln}^{\prime}$ pairs, can produce up to $90 \%$ of the desired hetero-bimetallic helicate. Indeed, extensions of this work further lead to the isolation of tri- and tetranuclear hetero-bimetallic complexes in much higher yield than predicted from a purely statistical standpoint. ${ }^{4}$ A related approach saw the use of a ditopic catechol/thiocatechol ligand

${ }^{a}$ Department of Chemical and Biological Sciences, University of

Huddersfield, Huddersfield, UK HD1 3DH.

E-mail: c.r.rice@hud.ac.uk; Fax:+44 (0)148-447-2182

${ }^{b}$ EPFL SB ISIC LCS, BCH 3307 (Bâtiment de chimie UNIL), CH-1015 Lausanne, Switzerland

$\dagger$ Electronic supplementary information (ESI) available: Details of synthesis and characterisation of ligands $\mathrm{L}^{1}-\mathrm{L}^{4}$ and $\left[\mathrm{HgZn}\left(\mathrm{L}^{1}\right)_{2}\right]^{4+}$; UV-vis spectrophotometric titration of $\mathrm{L}^{2}$ with $\mathrm{Zn}^{2+}$ and $\mathrm{Hg}^{2+}$. Full crystallographic refinement details. CCDC 730541 and 730542. For ESI and crystallographic data in CIF or other electronic format see DOI: $10.1039 / \mathrm{b} 908911 \mathrm{j}$ which, upon reaction with $\mathrm{Ti}^{3+}$ and $\mathrm{Mo}^{3+}$, formed a heterobimetallic triple-stranded helicate. ${ }^{5}$

In this paper we use a new class of ditopic segmental pyridyl-thiazole (py-tz) N-donor ligand (Scheme 1) to demonstrate an alternative strategy for selectively introducing different metals into polynuclear arrays. The simplest of these ligands, $\mathrm{L}^{1}$, contains two tridentate $\mathrm{N}_{3}$ binding domains which are structural isomers of one another. Self-assembly with $\mathrm{Hg}^{2+}$ or $\mathrm{Zn}^{2+}$ ions gives various isomers of a dinuclear double-stranded complex in solution. In the presence of both ions, however, only one species is formed in which the py-py-tz sequences bind to $\mathrm{Zn}^{2+}$ and the py-tz-py sequences bind to $\mathrm{Hg}^{2+}$. The metal/site specificity is attributed to the divergent nature of the three $\mathrm{N}$-donors in each tridentate domain, which varies according to the order in which the heterocycles appear in the sequence. When combined with a simple bidentate chelate for binding tetrahedral $\mathrm{Cu}^{+}$, the $\mathrm{Zn}^{2+} / \mathrm{Hg}^{2+}$ recognition effects displayed by the two tridentate units can be exploited for the self-assembly of a $\mathrm{Zn}^{2+} / \mathrm{Hg}^{2+} / \mathrm{Cu}^{+}$hetero-trimetallic helicate.

Ligand $\mathrm{L}^{1}$ (Scheme 1) was prepared by reaction of its methylene hydroxy- and chloro-substituted py-py-tz and py-tz-py constituents, respectively, in a Williamson ether synthesis. Purification of the reaction mixture gave $\mathrm{L}^{1}$ as a colourless solid (see ESI $\dagger$ ). ${ }^{6}$

Reaction of $\mathrm{L}^{1}$ with one equivalent of $\mathrm{Zn}\left(\mathrm{ClO}_{4}\right)_{2} \cdot 6 \mathrm{H}_{2} \mathrm{O}$ in $\mathrm{MeCN}$ gives a colourless solution for which ESI mass spectroscopy showed an intense peak at $m / z 1469$ corresponding to the dizinc(II) species $\left[\mathrm{Zn}_{2}\left(\mathrm{~L}^{1}\right)_{2}\left(\mathrm{ClO}_{4}\right)_{3}\right]^{+}$. The ${ }^{1} \mathrm{H}$ NMR $\left(\mathrm{CD}_{3} \mathrm{CN}\right)$ spectrum features two major sets of resonances, in addition to a third minor set which accounts for $<5 \%$ of the total ligand (peak integration also suggests that one of the
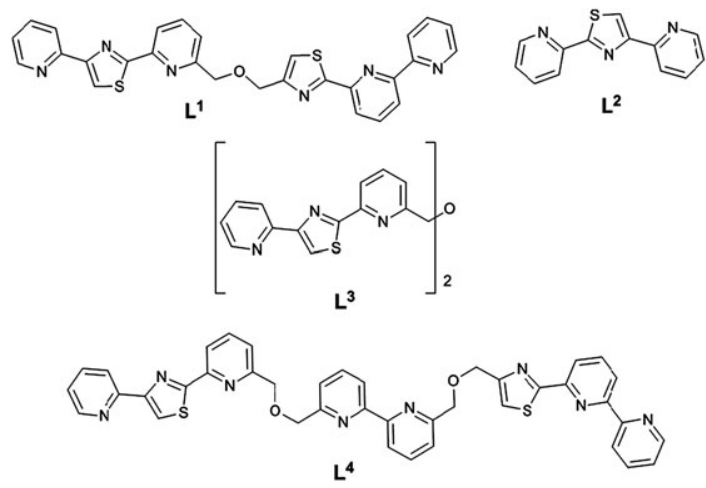

Scheme 1 


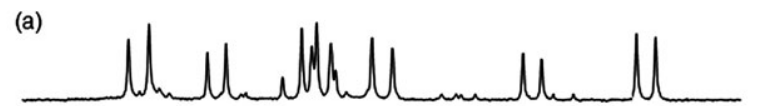

(b)

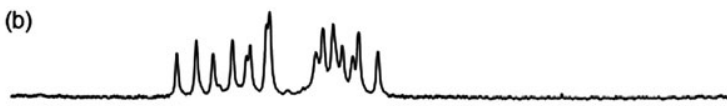

(c)

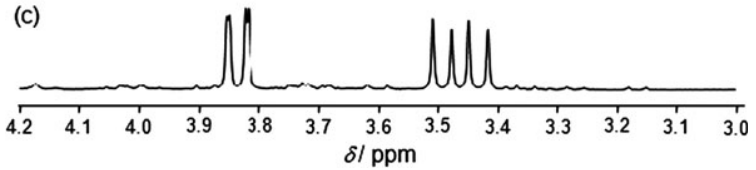

Fig. 1 Methylene regions in the ${ }^{1} \mathrm{H}$ NMR spectra $\left(\mathrm{CD}_{3} \mathrm{CN}\right)$ of (a) $\left[\mathrm{Zn}_{2}\left(\mathrm{~L}^{1}\right)_{2}\right]^{4+}$, (b) $\left[\mathrm{Hg}_{2}\left(\mathrm{~L}^{1}\right)_{2}\right]^{4+}$ and (c) $\left[\mathrm{HgZn}\left(\mathrm{L}^{1}\right)_{2}\right]^{4+}$.

major species is in slight excess of the other). The aliphatic region (4.1-3.1 ppm) contains four $\mathrm{AB}$ spin systems (eight doublets, Fig. 1a), which we attribute to the diastereotopic methylene protons in the $C_{2}$-symmetric $H H$ - and $H T$-isomers of a double-stranded dizinc(II) helicate $\left[\mathrm{Zn}_{2}\left(\mathrm{~L}^{1}\right)_{2}\right]^{4+}$. We note that the corresponding side-to-side mesocate complexes could also give rise to diastereotopic methylene groups, and that the latter observations are therefore not conclusive evidence for helical wrapping of the ligand strands about the dizinc(II) axes. However, the tendency for oxo-propylene-linked polytopic ligands to self-assemble into helicate structures has been demonstrated on numerous occasions, ${ }^{1,6}$ and on this basis we discount the possibility of the present system adopting non-helical conformers in solution. In a similar manner, self-assembly of $\mathrm{L}^{1}$ with $\mathrm{Hg}\left(\mathrm{ClO}_{4}\right)_{2} \cdot 4 \mathrm{H}_{2} \mathrm{O}$ in $\mathrm{MeCN}$ leads to the formation of the dimercury(II) complex $\left[\mathrm{Hg}_{2}\left(\mathrm{~L}^{1}\right)_{2}\right]^{4+}$, with a peak emerging at $m / z 1741$ in the ESI mass spectrum. Eight diastereotopic methylene protons in the ${ }^{1} \mathrm{H}$ NMR spectrum likewise indicate the occurrence of both $H H$ - and $H T$-isomers in approximately equal quantity (Fig. 1b).

Combining $\mathrm{L}^{1}$ with both $\mathrm{Hg}^{2+}$ and $\mathrm{Zn}^{2+}$ in the ratio $2: 1: 1$ results in the formation of a strikingly different species in solution. The ${ }^{1} \mathrm{H}$ NMR spectrum is greatly simplified (Fig. 1c and $\mathrm{ESI} \dagger$ ), and comparison with the spectra of the $\mathrm{Hg}^{2+}$ and $\mathrm{Zn}^{2+}$ complexes shows that none of the homometallic species are present (Fig. 1). The methylene groups remain diastereotopic, and the presence of only four such doublets points to the near exclusive formation of a $C_{2}$-symmetric hetero-bimetallic complex $H H$ - $\left[\mathrm{HgZn}\left(\mathrm{L}^{1}\right)_{2}\right]^{4+}$. This is corroborated by the ESI mass spectrum which shows an intense peak at $m / z \quad 1605$ for the perchlorate adduct $\left[\mathrm{HgZn}\left(\mathrm{L}^{1}\right)_{2}\left(\mathrm{ClO}_{4}\right)_{3}\right]^{+}$, and only minor peaks for analogous homo-dinuclear species (see ESI $\dagger$ ).

Structural characterisation was obtained from a single crystal X-ray diffraction study. $\ddagger$ As expected, the complex cation has a helicate conformation in the solid-state (Fig. 2), with both strands of $\mathrm{L}^{1}$ being aligned in a $H H$-manner along the central metal axis. The $\mathrm{Hg}^{2+}$ ion is pseudo-octahedrally coordinated by two near orthogonal py-tz-py units. The py-py-tz units are, however, host for a $\mathrm{Zn}^{2+}$ ion in only $c a .70 \%$ of the crystal. For the remainder, this site complexes another $\mathrm{Hg}^{2+}$ ion. The partial site occupancies of the metals are well-defined and have been modelled in conjunction with disorder in the coordinating py-py-tz rings, which alternate between one of two positions (Fig. 2). Not surprisingly, the terminal py rings move further away from the metal centre in the $c a .30 \%$ of the
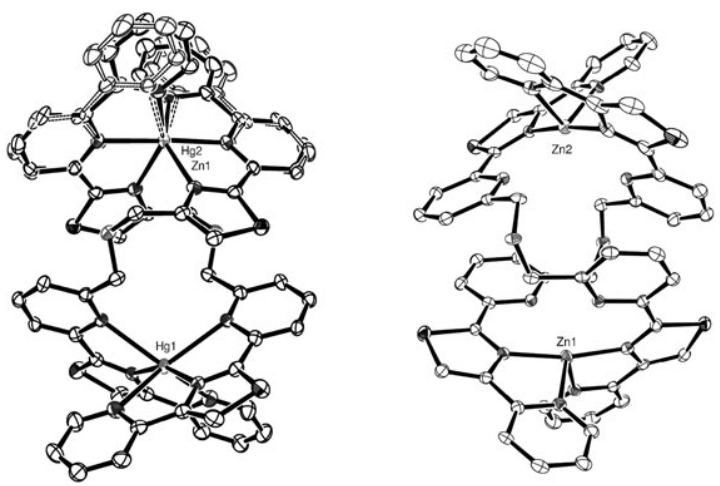

Fig. 2 Solid-state structures of $H H$ - $\left[\mathrm{Hg}_{1.3} \mathrm{Zn}_{0.7}\left(\mathrm{~L}^{1}\right)_{2}\right]^{4+}$ (left) showing major (solid bonds) and minor (open bonds) disorder components, and $\left[\mathrm{Zn}_{2}\left(\mathrm{~L}^{3}\right)_{2}\right]^{4+}$ (right).

crystal containing only the dimercury(II) helicate. We note that an identical picture was obtained from two independent measurements on crystals grown from different solutions of $H H$ - $\left[\mathrm{HgZn}\left(\mathrm{L}^{1}\right)_{2}\right]^{4+}$, despite the latter clearly being the predominant species present on both occasions. The metal/site scrambling observed in the solid-state is thus likely the result of kinetic resolution effects operating during the crystallisation process.

The high selectivity for $H H$ - $\left[\mathrm{HgZn}\left(\mathrm{L}^{1}\right)_{2}\right]^{4+}$ in solution is quite remarkable. Assuming that the self-assembly process gives only saturated helical conformers of first order complexity, ${ }^{7}$ then the observed $H H-\left[\mathrm{HgZn}\left(\mathrm{L}^{1}\right)_{2}\right]^{4+}$ is one of seven species (additionally: a $H H-\left[\mathrm{HgZn}\left(\mathrm{L}^{1}\right)_{2}\right]^{4+}$ in which the metals are inversed, $H T-\left[\mathrm{HgZn}\left(\mathrm{L}^{1}\right)_{2}\right]^{4+}, H H-\left[\mathrm{Hg}_{2}\left(\mathrm{~L}^{1}\right)_{2}\right]^{4+}$, $H T-\left[\mathrm{Hg}_{2}\left(\mathrm{~L}^{1}\right)_{2}\right]^{4+}, H H-\left[\mathrm{Zn}_{2}\left(\mathrm{~L}^{1}\right)_{2}\right]^{4+}$ and $\left.H T-\left[\mathrm{Zn}_{2}\left(\mathrm{~L}^{1}\right)_{2}\right]^{4+}\right)$ competing for $\mathrm{L}^{1}$ when ligand, $\mathrm{Zn}^{2+}$ and $\mathrm{Hg}^{2+}$ are combined in a $2: 1: 1$ ratio. In the absence of directing effects, $\S$ symmetry considerations $^{8}$ state that all seven species would form in a statistical $1: 1: 2: 1: 1: 1: 1$ ratio, respectively. That $H H-\left[\mathrm{HgZn}\left(\mathrm{L}^{1}\right)_{2}\right]^{4+}$ clearly presides in solution therefore requires that it be disposed to stabilising contributions which are absent in the other complexes.

The solid-state structure of $H H-\left[\mathrm{HgZn}\left(\mathrm{L}^{1}\right)_{2}\right]^{4+}$ holds nothing to suggest that inter-ligand interactions are responsible for its high relative stability. Intermetallic interactions ${ }^{4,9}$ and pre-organisation effects ${ }^{10}$ could be of more importance in determining the relative stabilities of the various possible complexes in equilibrium. We suspect, however, that the main reason for $H H$ - $\left[\mathrm{HgZn}\left(\mathrm{L}^{1}\right)_{2}\right]^{4+}$ being selected is that the two binding sites of $\mathrm{L}^{1}$ are structurally very different. Varying the position of the $t z$ ring from terminal (in py-py-tz) to central (in py-tz-py) has a pronounced effect on the respective bite angles of the tridentate chelates. ${ }^{11}$ It is likely, therefore, that the diffuse $\mathrm{Hg}^{2+}$ ion has a higher affinity for the geometrically more divergent py-tz-py unit, relative to the $\mathrm{Zn}^{2+}$ ion.

Stability constants (see ESI $\dagger$ ) for the $\mathrm{Zn}^{2+}$ and $\mathrm{Hg}^{2+}$ complexes of simple monotopic ligand $\mathrm{L}^{2}$ (Scheme 1) correlate with the proposed grounds for selectivity. Both ions form $\left[\mathrm{M}\left(\mathrm{L}^{2}\right)_{2}\right]^{2+}$ and $\left[\mathrm{M}\left(\mathrm{L}^{2}\right)_{3}\right]^{2+}$ complexes with $\mathrm{L}^{2}$, but those for $\mathrm{Hg}^{2+}\left(\beta_{1,2}=14.33(4) ; \beta_{1,3}=19.41(6)\right)$ are at least three log units higher in stability than those for $\mathrm{Zn}^{2+}\left(\beta_{1,2}=11.35(2)\right.$; $\left.\beta_{1,3}=16.59(3)\right)$. Structural evidence for the inferred enthalpic penalty is also provided by the solid-state structure of related 
complex $\left[\mathrm{Zn}_{2}\left(\mathrm{~L}^{3}\right)_{2}\right]^{4+}$, formed by self-assembly of $\mathrm{Zn}^{2+}$ with $C_{2 \mathrm{~h}}$-symmetric ligand $\mathrm{L}^{3}$ (Scheme 1). The latter features two py-tz-py units linked by an oxo-propylene bridge and, in an analogous manner to $\mathrm{L}^{1}$, self-assembles to give a dinuclear double-stranded helicate. Indeed, from the crystal structure of $\left[\mathrm{Zn}_{2}\left(\mathrm{~L}^{3}\right)_{2}\right]^{4+}$ (Fig. 2), it is clear that the py-tz-py units are too divergent for all three $\mathrm{N}$-donors to simultaneously coordinate the $\mathrm{Zn}^{2+}$ centres: $\mathrm{Zn}-\mathrm{N}$ separations for the outer $\mathrm{tz} /$ py rings lie in the range 1.962(3)-2.183(3) $\AA$, whilst those for the inner py rings are $2.551(3)-2.610(3) \AA$, distances too long to be considered bonding interactions.

The recognition effects displayed by the two tridentate units of $\mathrm{L}^{1}$ can be exploited for forming a hetero-trimetallic helicate. The insertion of a bidentate bipyridyl fragment into the middle of the ligand chain of $\mathrm{L}^{1}$ leads to the tritopic ligand $\mathrm{L}^{4}$ (Scheme 1), which is now coded for binding $\mathrm{Zn}^{2+}$ and $\mathrm{Hg}^{2+}$ in the terminal sites, and a tetrahedral ion, such as $\mathrm{Cu}^{+}$, in the central site of a double-stranded helicate. Thus, combining two equivalents of $\mathrm{L}^{4}$ with one each of $\mathrm{Zn}\left(\mathrm{ClO}_{4}\right)_{2} \cdot 6 \mathrm{H}_{2} \mathrm{O}$, $\mathrm{Hg}\left(\mathrm{ClO}_{4}\right)_{2} \cdot 4 \mathrm{H}_{2} \mathrm{O}$ and $\left[\mathrm{Cu}(\mathrm{MeCN})_{4}\right]\left[\mathrm{PF}_{6}\right]$ in $\mathrm{CD}_{3} \mathrm{CN}$ gives an immediate orange coloured solution, typical of the metal-to-ligand charge transfer transitions of $\left.[\mathrm{Cu} \text { (bipy })_{2}\right]^{+}$-type chromophores. The ESI mass spectrum shows peaks at $m / z 2347$ and 1101 for the hexafluorophosphate adducts $\left[\mathrm{HgCuZn}\left(\mathrm{L}^{4}\right)_{2}\left(\mathrm{PF}_{6}\right)_{4}\right]^{+}$and $\left[\mathrm{HgCuZn}\left(\mathrm{L}^{4}\right)_{2}\left(\mathrm{PF}_{6}\right)_{3}\right]^{2+}$, respectively, (Fig. 3), but a large number of other species are also clearly present. Peaks for the latter, however, diminish in intensity after tempering the solution at $60{ }^{\circ} \mathrm{C}$ for a week, consistent with their being kinetic products. ${ }^{1} \mathrm{H}$ NMR reflects these observations: early stage spectra show complicated mixtures of species, whilst only one set of peaks prevails on tempering the solution. The aliphatic region of one such spectrum, shown in Fig. 3c, clearly features eight doublets, as expected for the eight diastereotopic methylene groups in a $C_{2}$-symmetric $H H$ - $\left[\mathrm{HgCuZn}\left(\mathrm{L}^{4}\right)_{2}\right]^{5+}$ helicate. We note that whilst this species remains to be characterised in the solid-state, the proposed structure is one of a very few that adequately accounts for the ESI and ${ }^{1} \mathrm{H}$ NMR data.

In conclusion, we have shown how subtle geometric changes caused simply by varying the order of $\mathrm{N}$-heterocyclic rings in a

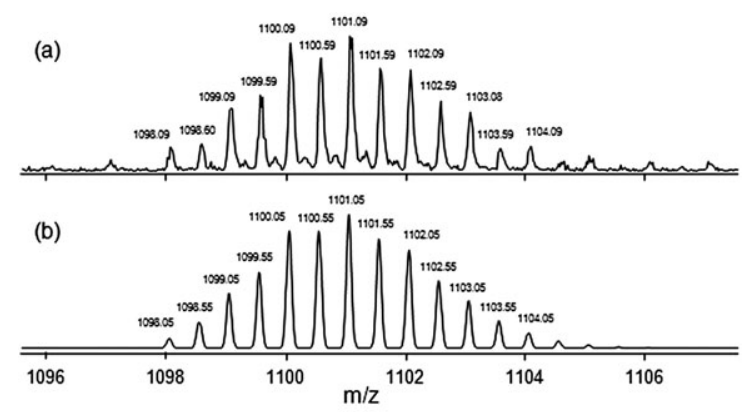

(c)

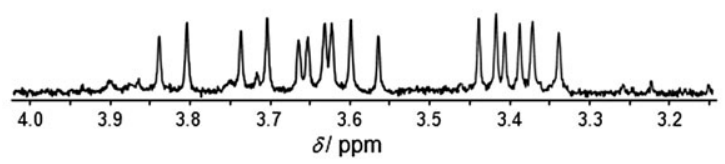

Fig. 3 (a) Observed and (b) calculated isotopic distribution patterns for molecular ion $\left[\mathrm{HgCuZn}\left(\mathrm{L}^{4}\right)_{2}\left(\mathrm{PF}_{6}\right)_{3}\right]^{2+}$, and (c) methylene region in the ${ }^{1} \mathrm{H}$ NMR spectrum $\left(\mathrm{CD}_{3} \mathrm{CN}\right)$ of $H H-\left[\mathrm{HgCuZn}\left(\mathrm{L}^{4}\right)_{2}\right]^{5+}$. tridentate binding unit can lead to pronounced recognition effects. These changes dramatically modify the size of the binding unit and, consequently, allow for metal ion selectivity to be tuned.

\section{Notes and references}

$\ddagger$ Crystal data for $H H$ - $\left[\mathrm{Hg}_{1.29} \mathrm{Zn}_{0.71}\left(\mathrm{~L}^{1}\right)_{2}\right]\left[\mathrm{ClO}_{4}\right]_{4} \cdot 2 \mathrm{Et}_{2} \mathrm{O} \cdot 1.42 \mathrm{MeCN}$ : $M=1951.57$, monoclinic $C 2 / c, a=21.571(3), b=16.707(2)$, $c=22.669(3) \AA, \beta=113.375(3)^{\circ}, V=7499.3(16) \AA^{3}, Z=4$; $\rho_{\text {calc }}=1.729 \mathrm{Mg} \mathrm{m}^{-3}, F(000)=3905$; crystal dimensions $0.20 \times$ $0.25 \times 0.10 \mathrm{~mm} ; \mu(\mathrm{MoK} \alpha)=0.71073 \mathrm{~mm}^{-1}, T=100 \mathrm{~K}$. A total of 35235 reflections were measured in the range $1.59 \leq \theta \leq 27.88^{\circ}$ ( $h k l$ range indices: $-28 \leq h \leq 28,-21 \leq k \leq 21,-29 \leq l \leq 26$ ), 8908 unique reflections $\left(R_{\text {int }}=0.0475\right)$. The structure was refined on $F^{2}$ to $R_{\mathrm{w}}=0.1197, R=0.0448$ (6780 reflections with $\left.I>2 \sigma(I)\right)$ and $\mathrm{GOF}=0.922$ on $F^{2}$ for 486 refined parameters, 132 restraints. Largest peak and hole 1.532 and $-0.833 \mathrm{eA}^{-3}$.

$\S$ i.e., in the unlikely event that (i) the metals have identical affinities for the two sites, with those in turn being identical, and (ii) all other microscopic interactions are invariant from one complex to another. ${ }^{4}$ - Crystal data for $\left[\mathrm{Zn}_{2}\left(\mathrm{~L}^{2}\right)_{2}\right]\left[\mathrm{ClO}_{4}\right]_{4} \cdot 3 \mathrm{MeCN} \cdot \mathrm{Et}_{2} \mathrm{O}: M=1767.06$, triclinic $P \overline{1}, a=12.4711(7), b=14.3884(9), c=22.2744(13) \AA$, $\alpha=101.269(1)^{\circ}, \beta=97.531(1)^{\circ}, \gamma=99.022(1)^{\circ}, V=3817.0(4) \AA^{3}$, $Z=2 ; \rho_{\text {calc }}=1.537 \mathrm{Mg} \mathrm{m}^{-3}, F(000)=1808 ;$ crystal dimensions $0.10 \times 0.07 \times 0.06 \mathrm{~mm} ; \mu(\mathrm{MoK} \alpha)=0.71073 \mathrm{~mm}^{-1}, T=100 \mathrm{~K}$ A total of 67179 reflections were measured in the range $0.95 \leq \theta \leq 27.48^{\circ}$ ( $h k l$ range indices: $-16 \leq h \leq 16,-18 \leq k \leq 18,-28 \leq l \leq 28$ ), 17470 unique reflections $\left(R_{\text {int }}=0.0745\right)$. The structure was refined on $F^{2}$ to $R_{\mathrm{w}}=0.1445, R=0.0561$ (10293 reflections with $\left.I>2 \sigma(I)\right)$ and $\mathrm{GOF}=0.881$ on $F^{2}$ for 882 refined parameters, largest peak and hole 0.611 and $-0.699 \mathrm{e}^{-3}$.

1 J.-M. Lehn, Supramolecular Chemistry, VCH, Weinheim, 1995; M. Albrecht, Chem. Soc. Rev., 2001, 101, 3547; C. Piguet, G. Bernardinelli and G. Hopfgartner, Chem. Rev., 1997, 97, 2005; E. C. Constable, Comprehensive Supramolecular Chemistry, in Polynuclear Transition Metal Helicates, ed. J.-P. Sauvage, Elsevier, Oxford, 1996, vol. 9, p. 213; R. Krämer, J.-M. Lehn and A. Marquis-Rigault, Proc. Natl. Acad. Sci. U. S. A., 1993, 90, 5394

2 E. C. Constable, A. J. Edwards, P. R. Raithby, D. R. Smith, J. V. Walker and L. Whall, Chem. Commun., 1996, 2551; S. P. Argent, H. Adams, L. P. Harding, T. Riis-Johannessen, J. C. Jeffery and M. D. Ward, New J. Chem., 2005, 29, 904; E. C. Constable and J. V. Walker, J. Chem. Soc., Chem. Commun., 1992, 884; E. C. Constable, A. J. Edwards, R. Raithby and J. V. Walker, Angew. Chem., Int. Ed. Engl., 1993, 32, 1465; K. T. Potts, M. Keshavarz-K, F. S. Tham, H. D. Abruna and C. Arana, Inorg. Chem., 1993, 32, 4422.

3 N. André, R. Scopelliti, G. Hopfgartner, C. Piguet and J.-C. G. Bünzli, Chem. Commun., 2002, 214; N. André, T. B. Jensen, R. Scopelliti, D. Imbert, M. Elhabiri, G. Hopfgartner, C. Piguet and J.-C. G. Bünzli, Inorg. Chem., $2004, \mathbf{4 3}, 515$.

4 S. Floquet, M. Borkovec, G. Bernardinelle, A. Pinto, L.-A. Leuthold, G. Hopfgartner, D. Imbert, J.-C. G. Bünzli and C. Piguet, Chem.-Eur. J., 2004, 10, 1091; N. Dalla-Favera, J. Hamacek, M. Borkovec, D. Jeannerat, G. Ercolani and C. Piguet, Inorg. Chem., 2007, 46, 9312.

5 F. Ekkehardt Hahn, M. Offermann, C. S. Isfort, T. Pape and R. Fröhlich, Angew. Chem., Int. Ed., 1998, 47, 6794.

6 T. Riis-Johannessen, L. P. Harding, J. C. Jeffery, R. Moon and C. R. Rice, Dalton Trans., 2007, 1577.

7 J.-M. Senegas, S. Koeller and C. Piguet, Chem. Commun., 2005, $2235-2237$.

8 G. Ercolani, C. Piguet, M. Borkovec and J. Hamacek, J. Phys. Chem. B, 2007, 111, 12195.

9 G. Canard and C. Piguet, Inorg. Chem., 2007, 46, 3511-3522.

10 G. Canard, S. Koeller, G. Bernardinelli and C. Piguet, J. Am. Chem. Soc., 2008, 130, 1025-1040.

11 C. R. Rice, S. Wörl, J. C. Jeffery, R. L. Paul and M. D. Ward, J. Chem. Soc., Dalton Trans., 2001, 550; C. R. Rice, S. Wörl, J. C. Jeffery, R. L. Paul and M. D. Ward, Chem. Commun., 2000, 1529. 